\title{
Clinical utility of PDSS2 expression to stratify patients at risk for recurrence of hepatocellular carcinoma
}

\author{
MITSURO KANDA, HIROYUKI SUGIMOTO, SHUJI NOMOTO, HISAHARU OYA, DAI SHIMIZU, \\ HIDEKI TAKAMI, RYOJI HASHIMOTO, FUMINORI SONOHARA, YUKIYASU OKAMURA, SUGURU YAMADA, \\ TSUTOMU FUJII, GORO NAKAYAMA, MASAHIKO KOIKE, MICHITAKA FUJIWARA and YASUHIRO KODERA
}

\author{
Department of Gastroenterological Surgery (Surgery II), Nagoya University Graduate School of Medicine, Nagoya, Japan
}

Received July 1, 2014; Accepted August 21, 2014

DOI: $10.3892 /$ ijo.2014.2637

\begin{abstract}
Identification of novel genetic and epigenetic alterations is required for optimal stratification of patients with hepatocellular carcinoma (HCC) at risk for recurrence and adverse prognosis. Coenzyme Q10 (CoQ10), which mediates apoptosis, is synthesized by prenyl diphosphate synthase subunit 2(PDSS2). In the present study we evaluated the clinical significance and regulatory mechanisms of PDSS2 expression in HCC. PDSS2 expression levels and those of genes encoding potentially interacting proteins as well as the methylation status of the PDSS2 promoter region were analyzed in HCC cell lines. PDSS 2 mRNA levels in 151 pairs of resected specimens were determined to evaluate the association of PDSS2 expression and clinicopathological factors. The expression and distribution of PDSS2 were determined using immunohistochemistry. PDSS2 mRNA expression was decreased in six of nine HCC cell lines and significantly correlated with those of hepatocyte nuclear factor $4 \alpha$. PDSS 2 transcription in HCC cells with decreased PDSS 2 expression accompanying hypermethylation was reactivated after treating these cells with a methylation inhibitor. Mean expression levels of PDSS2 mRNA relative to that of uninvolved liver diminished gradually in the order of chronic hepatitis to cirrhosis, and each was significantly higher than those of HCCs. PDSS2 and PDSS2 mRNA levels were consistent. Decreased PDSS2 mRNA levels were detected in HCC tissues of 56 patients, correlated with shorter disease-specific survival, and was identified as an independent prognostic factor. PDSS2 is a putative tumor suppressor, and promoter hypermethylation is a key regulatory mechanism in HCC. Decreased levels of PDSS2 mRNA expression may represent a novel biomarker of HCC.
\end{abstract}

Correspondence to: Dr Mitsuro Kanda, Department of Gastroenterological Surgery (Surgery II), Nagoya University Graduate School of Medicine, 65 Tsurumai-cho, Showa-ku, Nagoya 466-8550, Japan

E-mail: m-kanda@med.nagoya-u.ac.jp

Key words: prenyl diphosphate synthase subunit 2, expression, hepatocellular carcinoma, methylation, recurrence

\section{Introduction}

Hepatocellular carcinoma (HCC) is one of the most lethal cancers worldwide and is the main cause of death among cirrhotic patients (1-3). Patients diagnosed with HCC have a poor prognosis because of the aggressive nature of the disease $(4,5)$, and surgical resection or local ablation therapy is effective only at an early stage (6). Furthermore, $~ 70 \%$ of these patients develop recurrent tumors within five years after curative surgery (7). Recurrence of HCC, including multicentric hepatocarcinogenesis and intrahepatic metastasis, is a key prognostic factor, but it is difficult to distinguish patients at high risk for recurrence and subsequent adverse prognosis using only clinical staging systems comprising tumor characteristics and liver function $(1,8)$. Therefore, a novel approach for predicting progression and recurrence of $\mathrm{HCC}$ is urgently required.

Liver damage and the increased incidence of HCC (chronic viral hepatitis $\mathrm{B}$ and $\mathrm{C}$, alcohol consumption and aflatoxin) have multiple causes $(5,9,10)$. Furthermore, as with other malignancies, the initiation of $\mathrm{HCC}$ is a multistep process, and because it is characterized by high molecular variability, clinical management requires a more complex approach (11).

Although recent research along with the development of new genomic technologies establishes that the development and progression of HCC are caused by the accumulation of genetic and epigenetic alterations (12-14), the detailed underlying mechanisms have not been determined. Therefore, identifying molecular markers for HCC, particularly those that may predict recurrence, is important, because stratification of patients at risk for recurrence facilitates individualized management, including intensive surveillance and aggressive adjuvant therapy for high-risk patients.

Prenyl diphosphate synthase subunit 2 (PDSS2) was identified in 2005 (15), it encodes the second subunit of prenyl diphosphate synthase, which is an essential enzyme involved in the biosynthesis of coenzyme Q10 (CoQ10), and PDSS2 determines the side-chain length of mammalian ubiquinones (16). CoQ10 is synthesized from mevalonic acid in the liver and plays a vital role in the mitochondrial respiratory chain, pyrimidine nucleoside biosynthesis and the modulation of cell apoptosis (17). Aberrant expression of PDSS2 in the liver may cause DNA damage and disrupt the cell cycle through inhibi- 
tion of CoQ10 synthesis, leading to initiation and progression of HCC $(18,19)$. Furthermore, chronic inflammation caused by hepatitis virus infection might affect PDSS2 expression. Although evidence indicates that PDSS2 suppresses the development of malignant melanoma and lung cancer $(16,20)$, the clinical significance and regulatory mechanisms of PDSS2 expression in HCC remain undefined.

Therefore, we attempted to answer these questions in the present study by analyzing PDSS 2 expression in HCC to identify novel, clinically significant biomarkers for progression and recurrence of HCC. To the best of our knowledge, this is the first report to determine PDSS2 expression levels in HCC.

\section{Materials and methods}

Sample collection. Nine HCC cell lines (Hep3B, HepG2, HLE, HLF, HuH1, HuH2, HuH7, PLC/PRF/5 and SK-Hep1) were obtained from the American Type Culture Collection (ATCC, Manassas, VA, USA) and were maintained as previously described (21). Primary HCC and non-cancerous tissues were collected from 151 patients who underwent liver resection for HCC at Nagoya University Hospital between January 1998 and July 2012. Clinicopathological data were collected from medical records. Specimens were classified histologically according to the 7th Edition of the Union for International Cancer Control classification (22).

Tissue samples were immediately flash-frozen in liquid nitrogen and stored at $-80^{\circ} \mathrm{C}$. RNA was extracted from $\sim 5 \mathrm{~mm}^{2}$ diameter tumor samples without detectable necrotic areas comprising $>80 \%$ tumor cells. The corresponding non-cancerous liver tissue samples that lacked regenerative or dysplastic nodules were collected from the same patient that were $>2 \mathrm{~cm}$ distant from the edge of the tumor. The median duration of patient follow-up was 37.9 months (range, 0.37-147 months). Postoperative follow-up included physical examinations, measurement of serum tumor markers every three months, and enhanced computed tomography scans every six months. Treatment after recurrence was generally selected from one of the options as follows: surgery, radiofrequency ablation, transcatheter arterial chemoembolization, and chemotherapy, according to tumor status and liver function. Enrollees granted written informed consent for the use of clinical samples and data as required by the Institutional Review Board of Nagoya University, Japan.

Quantitative real-time reverse-transcription polymerase chain reaction ( $q R T-P C R)$. PDSS 2 mRNA levels were determined using qRT-PCR. Total RNA $(10 \mu \mathrm{g})$ was isolated from 9 HCC cell lines, 151 primary HCCs and adjacent non-cancerous tissues, and was used as a template for cDNA synthesis. Glyceraldehyde-3-phosphate dehydrogenase (GAPDH) mRNA (TaqMan, GAPDH control reagents; Applied Biosystems, Foster City, CA, USA) was quantified in each sample for standardization. Quantitative real-time RT-PCR was performed using the SYBR ${ }^{\circledR}$ Green PCR Core Reagents kit (Applied Biosystems) as follows: one cycle at $95^{\circ} \mathrm{C}$ for $10 \mathrm{~min}, 40$ cycles at $95^{\circ} \mathrm{C}$ for $5 \mathrm{sec}$, and $60^{\circ} \mathrm{C}$ for $60 \mathrm{sec}$. Real-time detection of the SYBR ${ }^{\circledR}$ Green fluoresence was conducted using an ABI StepOnePlus ${ }^{\mathrm{TM}}$ Real-Time PCR System (Applied Biosystems). Triplicate samples of 9 HCC cell lines and 151 clinical samples were analyzed. Samples without templates served as negative controls. The expression level of each sample is shown as the value of the PDSS2 amplicon divided by that of GAPDH (23). The primer sequences are listed in Table I. PDSS 2 mRNA levels were considered downregulated in tumor tissues when they were $<50 \%$ compared with those of the corresponding non-cancerous tissues.

Analysis of the promoter region of PDSS2. The nucleotide sequence of the PDSS2 promoter region was analyzed to determine the presence or absence of $\mathrm{CpG}$ islands defined as follows: at least a 200-bp region of DNA with a high HCC content $(>50 \%)$ and an Observed $\mathrm{CpG} /$ Expected $\mathrm{CpG}$ ratio $\geq 0.6(24,25)$. CpG Island Searcher software (http://cpgislands. usc.edu/) was employed to determine the locations of $\mathrm{CpG}$ islands (26).

Methylation-specific PCR (MSP) and bisulfite sequence analysis. PDSS2 possesses a $\mathrm{CpG}$ island near its promoter region, and we hypothesized that aberrant methylation regulates PDSS2 transcription in HCC. DNA samples from nine HCC cell lines treated with bisulfite were subjected to MSP. Genomic bisulfite-treated DNA from HCC cell lines was sequenced to ascertain whether the MSP amplification was reliable. The primer sequences used for MSP and bisulfite sequencing are listed in Table I. Bisulfite treatment and the sequencing procedure were performed as reported (27).

5-Aza-2'-deoxycytidine (5-aza-dC) treatment. To assess the relation of promoter hypermethylation to $P D S S 2$ transcription, HCC cells $\left(1.5 \times 10^{6}\right)$ were treated with 5 -aza-dC (SigmaAldrich, St. Louis, MO, USA) to inhibit DNA methylation and cultured for 6 days with medium changes on days 1, 3 and 5 . RNA was extracted, and RT-PCR was performed as previously described (27).

Expression of genes encoding proteins potentially associated with PDSS2. The expression levels of hepatocyte nuclear factor $4 \alpha$ (HNF4 $\alpha$ ) and caudal-type homeobox transcription factor 2 (CDX2), which may associate with PDSS2 $(20,28)$ were determined in HCC cell lines using qRT-PCR. The sequences of primers specific for $\mathrm{HNF} 4 \alpha$ and CDX2 are listed in Table I.

Immunohistochemistry (IHC). IHC analysis of the localization of PDSS2 was performed using a mouse monoclonal antibody against PDSS2 (ab119768; Abcam, Cambridge, UK) diluted 1:150 in antibody diluent (Dako, Glostrup, Denmark) to probe 30 representative sections of well-preserved HCC tissue previously described (2). Staining patterns were compared between HCCs and the corresponding normal adjacent tissues. To avoid subjectivity, the specimens were randomized and coded before analysis by two independent observers who were unaware of the status of the samples. Each observer evaluated all specimens at least twice to minimize intraobserver variation (29).

Statistical analysis. Correlations between the levels of PDSS2 mRNA with those of HNF4 $\alpha$ and CDX2 were analyzed using the Spearman rank correlation test. Relative levels of mRNA expression (PDSS2/GAPDH) between HCC and non- 
Table I. Primers and annealing temperatures.

\begin{tabular}{|c|c|c|c|c|c|}
\hline Gene & Experiment & Type & Sequence $\left(5^{\prime}-3^{\prime}\right)$ & $\begin{array}{l}\text { Product size } \\
\text { (bp) }\end{array}$ & $\begin{array}{c}\text { Annealing } \\
\text { temperature }\left({ }^{\circ} \mathrm{C}\right)\end{array}$ \\
\hline \multirow[t]{8}{*}{ PDSS2 } & qRT-PCR & Forward & GAATCAGGTAGTGTCAGAGG & 181 & 60 \\
\hline & & Reverse & GAGGCTATTCCAGCTGTCATG & & \\
\hline & MSP methylated & Forward & TCGAAGTTGGATTCGAGGAT & 263 & 62 \\
\hline & & Reverse & AAACGTCGAACGAAAACACC & & \\
\hline & MSP unmethylated & Forward & GGTTGGTGGTGATAGTGATA & 195 & 56 \\
\hline & & Reverse & СААСАААТААТСССТСТАСАС & & \\
\hline & Bisulfite sequencing & Forward & TGTTTGGTTGGGTTTTGAGG & 152 & 58 \\
\hline & & Reverse & CACCAACCCCТА ACA ATA AC & & \\
\hline \multirow[t]{2}{*}{$H N F 4 \alpha$} & qRT-PCR & Forward & CGTGGTGGACAAAGACAAGA & 128 & 60 \\
\hline & & Reverse & CATAGCTTGACCTTCGAGTGC & & \\
\hline \multirow[t]{2}{*}{$C D X 2$} & qRT-PCR & Forward & GGAACCTGTGCGAGTGGAT & 128 & 60 \\
\hline & & Reverse & GAAАСТCСТTCTCCAGCTCC & & \\
\hline \multirow[t]{3}{*}{$G A P D H$} & qRT-PCR & Forward & GAAGGTGAAGGTCGGAGTC & 226 & 60 \\
\hline & & Probe & CAAGCTTCCCGTTCTCAGCC & & \\
\hline & & Reverse & GAAGATGGTGATGGGATTTC & & \\
\hline
\end{tabular}

PDSS2, prenyl diphosphate synthase subunit 2; HNF4 , hepatocyte nuclear factor $4 \alpha ; C D X 2$, caudal-related homeobox transcription factor 2; GAPDH, glyceraldehyde-3-phosphate dehydrogenase; qRT-PCR, quantitative real-time reverse-transcription polymerase chain reaction; MSP, methylation specific PCR; bp, base pair.

cancerous tissues were analyzed using the Mann-Whitney $U$ test. The $\chi^{2}$ test was used to analyze the significance of the association between the expression and methylation status of PDSS2 and clinicopathological parameters. Disease-specific and disease-free survival rates were calculated using the Kaplan-Meier method, and the difference in survival curves was analyzed using the log-rank test. We performed multivariate regression analysis using the Cox proportional hazards model to detect prognostic factors, and variables with $\mathrm{P}<0.05$ were entered into the final model. All statistical analyses were performed using JMP 10 software (SAS Institute, Inc., Cary, $\mathrm{NC}$, USA). $\mathrm{P}<0.05$ was considered statistically significant.

\section{Results}

Identification of a CpG island in the PDSS2 promoter region. A $\mathrm{CpG}$ island was identified in the $P D S S 2$ promoter region (Fig. 1A), leading to the hypothesis that hypermethylation of the $\mathrm{CpG}$ islands regulates the expression of PDSS2 in HCC.

PDSS2 mRNA expression and regulatory mechanisms in $H C C$ cell lines. Significant decrease in PDSS2 mRNA levels was detected in $6(67 \%)$ of 9 HCC cell lines compared with the mean expression level in 151 non-cancerous liver tissues (Fig. 1B). Hypermethylation of the PDSS2 promoter was detected in Hep3B, HuH2, HuH7 and SK-Hep1 cells (Fig. 1B). To determine whether hypermethylation of the PDSS2 promoter inhibited expression, PDSS 2 mRNA expression levels were compared before and after treatment with the methylation inhibitor 5-aza-dC. PDSS2 mRNA levels were restored in cells with downregulated PDSS2 expression accompanying hypermethylation after 5-aza-dC treatment (Fig. 1B), indicating that promoter hypermethylation inhibited PDSS2 transcription in HCC.

Expression of genes encoding proteins potentially associated with PDSS2 in HCC cell lines. The relative mRNA expression levels of PDSS2, HNF4 $\alpha$ and CDX2 in HCC cell lines are shown in Fig. 2A. PDSS2 expression levels significantly correlated with those of $H N F 4 \alpha$ (Fig. 2B).

Patient characteristics. The mean age of the 151 patients was 64.6 \pm 9.7 years (range, $34-84$ years), the male to female ratio was 5:1, and there were 37 and 84 patients with hepatitis B and $\mathrm{C}$ virus infections, respectively. Of the patients without $\mathrm{HCC}$, 10, 87 and 54 presented with normal liver function, chronic hepatitis or cirrhosis, respectively. We classified 140 and 11 patients as Child-Pugh class A or B, respectively.

Expression levels of PDSS2 $\mathrm{mRNA}$ and protein in resected tissues. The mean level of PDSS2 mRNA compared with that of non-cancerous liver diminished gradually in the order of normal liver, chronic hepatitis and cirrhosis, indicating that chronic inflammation and fibrosis of non-cancerous liver decreased PDSS2 expression (Fig. 3A). In contrast, the type of hepatitis virus infection (hepatitis virus $\mathrm{B}, \mathrm{C}$ or none) did not influence PDSS 2 expression in non-cancerous liver tissues. 
A

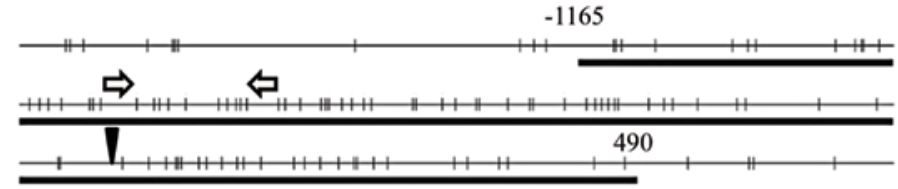

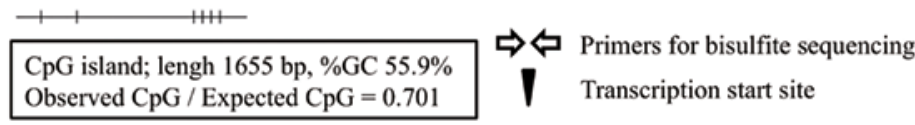

$\mathrm{B}$

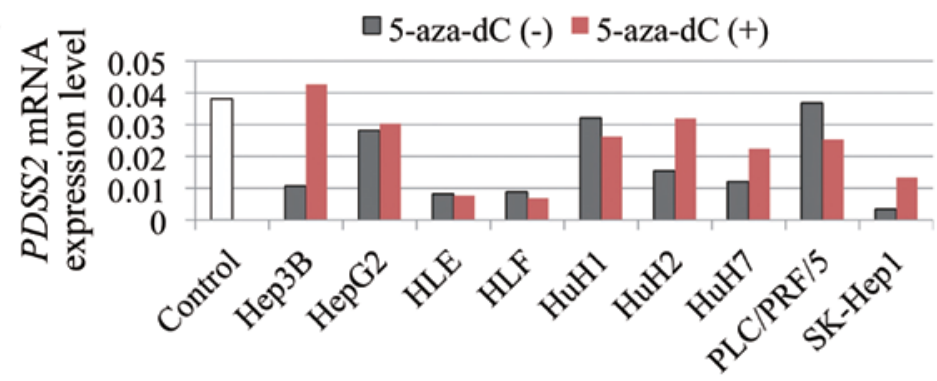

PDSS2 MSP $\equiv---\cdots--$

\begin{tabular}{ll|l|l|l|l|l|l|l|l|}
\hline Methylation & $\mathrm{M}$ & $\mathrm{U}$ & $\mathrm{U}$ & $\mathrm{U}$ & $\mathrm{U}$ & $\mathrm{M}$ & $\mathrm{pM}$ & $\mathrm{U}$ & $\mathrm{pM}$ \\
\hline
\end{tabular}

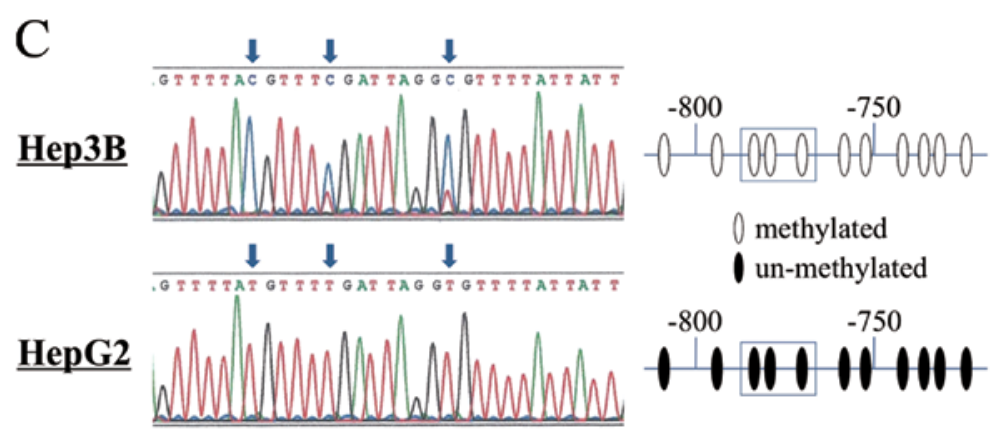

Figure 1. (A) A CpG island was detected near the PDSS2 transcription initiation site, extending upstream into the promoter region. (B) Bar graphs indicate PDSS2 mRNA expression in HCC cell lines before or after 5-aza-dC treatment. The methylation status of the PDSS2 promoter is shown in the box. M, methylated; pM, partially methylated; U, unmethylated. (C) Representative results of bisulfite sequence analysis. All CpG sites in Hep3B cells were retained as CG and those of HepG2 cells were converted to TG.
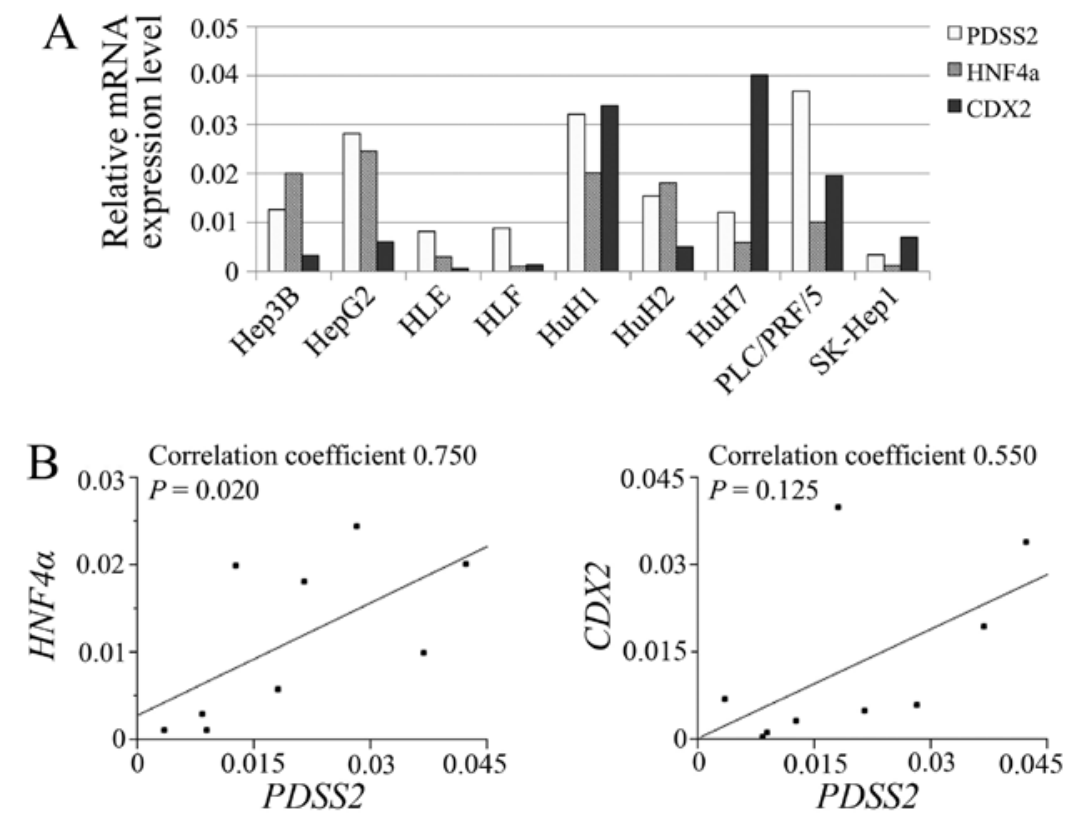

Figure 2. (A) Analysis of PDSS2, HNF4 $\alpha$ and CDX2 mRNA expression in HCC cell lines. (B) Comparison of mRNA expression levels between PDSS2, $H N F 4 \alpha$ and $C D X 2$. 

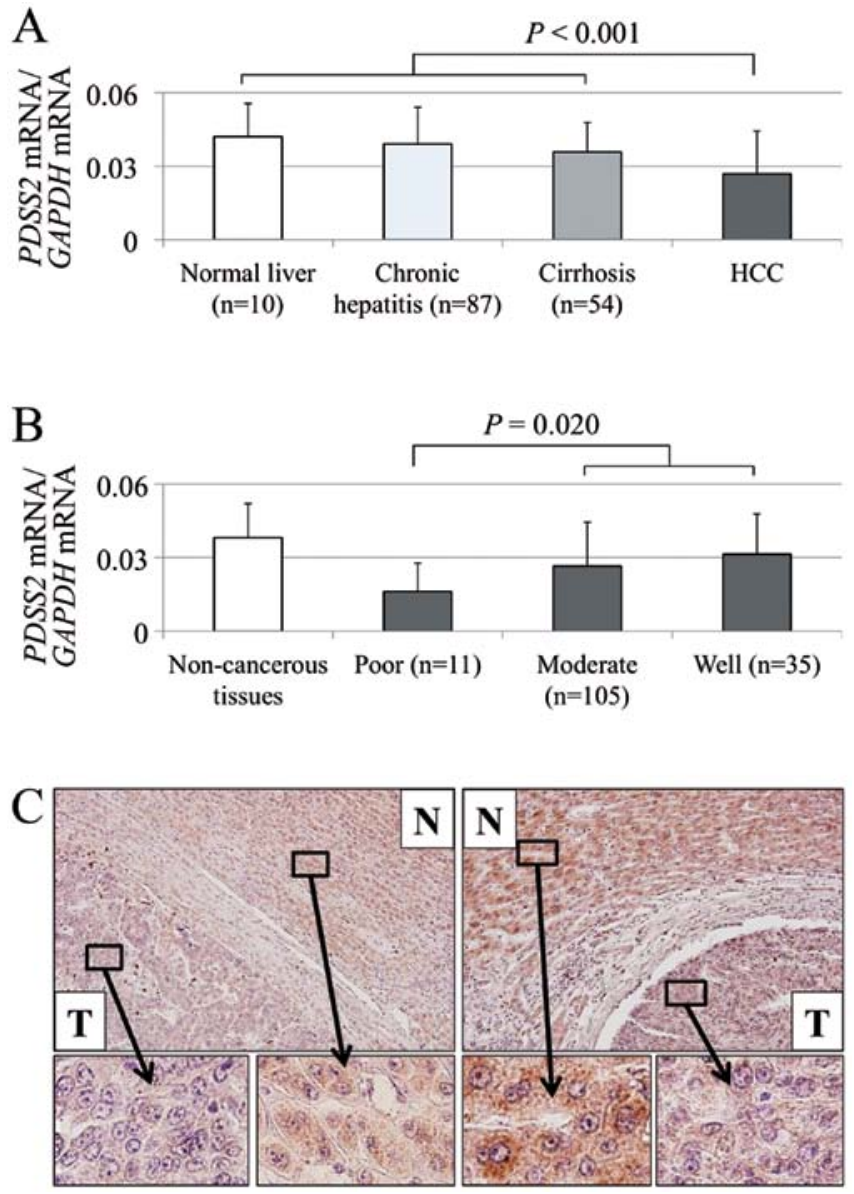

Figure 3. Analysis of the expression of PDSS2 in clinical specimens. (A) The mean level of PDSS2 mRNA expression was lower in HCC tissues compared with the corresponding non-cancerous tissues categorized by background uninvolved liver status. (B) Comparison of PDSS2 mRNA expression level among HCCs categorized by tumor differentiation. (C) Representative IHC data. PDSS2 was expressed at lower levels compared with non-cancerous adjacent tissue (magnified at x100 and $\mathrm{x} 400$ ). N, non-cancerous tissue; T, tumor tissue.

PDSS2 mRNA expression was decreased in HCC tissues of 122 (81\%) of 151 patients compared with that of the corresponding non-cancerous tissues. The mean expression level of PDSS2 mRNA was significantly lower in HCC tissues compared with that of the corresponding non-cancerous tissues $(\mathrm{P}<0.001$; Fig. 3A). Moreover, poorly differentiated tumor cells expressed relatively lower levels of PDSS2 mRNA (Fig. 3B).

The expression of PDSS2 was analyzed using IHC. Representative sections with reduced PDSS2 staining in HCC tissues are shown in Fig. 3C. The overall staining intensities of 30 samples were consistent with mRNA levels detected using qRT-PCR.

Prognostic implications of PDSS2 mRNA expression levels. Fifty-six (37\%) of 151 patients were categorized with decreased PDSS2 mRNA levels in HCC tissues compared with noncancerous tissues. The disease-specific survival rate of patients with HCC with decreased PDSS2 mRNA was significantly lower compared with those without this factor (5-year survival rates, 51 and $74 \%$, respectively, $\mathrm{P}=0.001$; Fig. $4 \mathrm{~A}$ ). Decreased PDSS2 mRNA expression in patients with HCCs was significantly associated with uninvolved liver status, preoperative
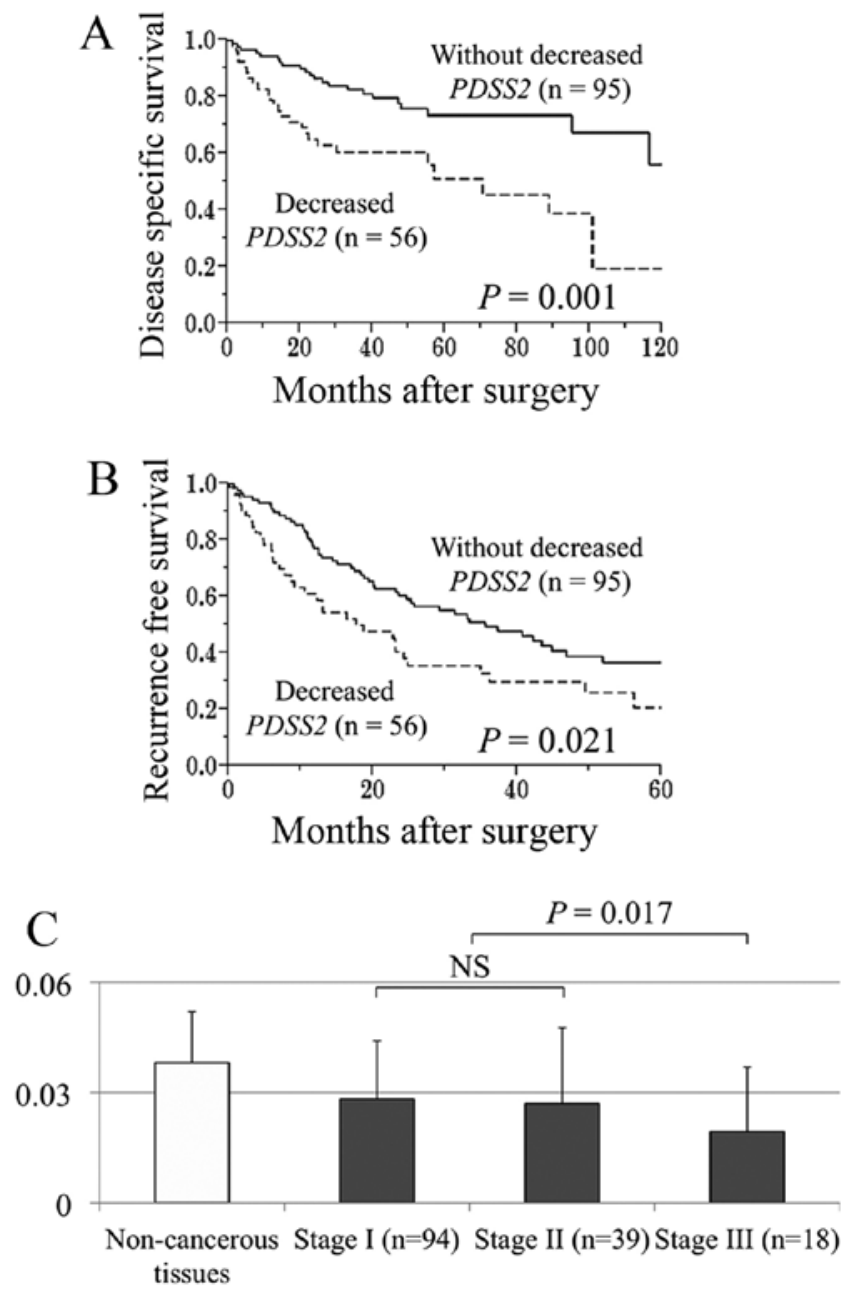

Figure 4. Prognostic significance of PDSS2 mRNA expression in patients with HCC. (A) Disease-specific survival of patients with decreased PDSS2 mRNA in HCC was significantly shorter than those without. (B) Recurrencefree survival of patients with decreased PDSS2 mRNA was significantly shorter than those without. (C) PDSS2 expression levels in each UICC stage.

serum $\alpha$-fetoprotein $>20 \mathrm{ng} / \mathrm{ml}$, tumor size $\geq 3.0 \mathrm{~cm}$, tumor differentiation (moderate to poor), serosal infiltration, septum formation and advanced UICC stage (Table II). Multivariate analysis identified decreased PDSS 2 mRNA expression as an independent prognostic factor (hazard ratio $2.45,95 \%$ confidence interval 1.27-4.80, $\mathrm{P}=0.008$; Table III). Patients with HCC with decreased PDSS2 mRNA levels experienced significantly earlier recurrences compared with those without (2-year recurrence-free survival rates, 38 and 59\%, respectively, $\mathrm{P}=0.021$; Fig. 4B). A stepwise decrease of PDSS mRNA expression in patients with HCC correlated with UICC stage (Fig. 4C).

\section{Discussion}

In the present study, our data support the role of PDSS2 as a suppressor of HCC. PDSS2 mRNA was differentially expressed by HCC cell lines and was decreased in $81 \%$ of the HCC tissues. Hypermethylation of the PDSS2 promoter was detected in four HCC cell types that expressed low levels of PDSS2 mRNA. Moreover, PDSS2 mRNA synthesis was reactivated after demethylation, indicating that promoter 
Table II. Association between expression levels of PDSS2 mRNA and clinicopathological parameters in 151 patients with hepatocellular carcinoma (HCC).

\begin{tabular}{lcll}
\hline & Decreased & & \\
& $P D S S 2$ & & \\
Clinicopathological & in HCCs & Others & \\
parameters & $(\mathrm{n}=56)$ & $(\mathrm{n}=95)$ & P-value \\
\hline
\end{tabular}

Age (years)
$<65$
$\geq 65$

26

30

41

54

Gender

Male

Female

50

6

76

19

Background liver

Normal liver

Chronic hepatitis

Cirrhosis

Pugh-Child's classification

$$
\text { A }
$$

Hepatitis virus

Absent
HBV
HCV
AFP $(\mathrm{ng} / \mathrm{ml})$
$\leq 20$
$>20$
PIVKA II $(\mathrm{mAU} / \mathrm{ml})$
$\leq 40$
$>40$

Tumor multiplicity

$$
\text { Solitary }
$$

Multiple

Tumor size $(\mathrm{cm})$

$$
\begin{aligned}
& <3.0 \\
& \geq 3.0
\end{aligned}
$$

0.696

0.128

$0.046^{\mathrm{a}}$

0.959

Differentiation

Well

Moderate to poor

Growth type

Expansive growth

Invasive growth

Serosal infiltration

Absent

Present

Formation of capsule

$$
\text { Absent }
$$

Present

Infiltration to capsule
Table II. Continued.

\begin{tabular}{lccc}
\hline & $\begin{array}{c}\text { Decreased } \\
\text { PDSS2 }\end{array}$ & & \\
Clinicopathological & $\begin{array}{c}\text { in HCCs } \\
(\mathrm{n}=56)\end{array}$ & $\begin{array}{c}\text { Others } \\
(\mathrm{n}=95)\end{array}$ & P-value \\
parameters & & & \\
\hline Septum formation & 13 & 40 & $0.017^{\mathrm{a}}$ \\
Absent & 43 & 55 & \\
Present & & & \\
Vascular invasion & 33 & 81 & $<0.001^{\mathrm{a}}$ \\
Absent & 23 & 14 & \\
Present & & & \\
UICC pathological stage & 27 & 67 & $0.014^{\mathrm{a}}$ \\
I & 18 & 21 & \\
II & 11 & 7 & \\
III & & & \\
\hline
\end{tabular}

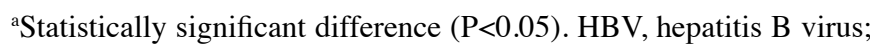
$\mathrm{HCV}$, hepatitis C virus; AFP, $\alpha$-fetoprotein; PIVKA, protein induced by vitamin K antagonists; UICC, Union for International Cancer Control.

hypermethylation regulated PDSS2 transcription. To the best of our knowledge, the present study is the first to show a correlation between the expression and methylation status of PDSS2. However, decreased transcription of PDSS2 was detected in some HCC cells without hypermethylation of the $P D S S 2$ promoter. Because PDSS2 is located within chromosome $6 \mathrm{q} 16.3-21$, a site of frequent loss of heterozygosity $(\mathrm{LOH})$ in HCC $(30,31)$, we consider $\mathrm{LOH}$ as a possible alternative factor leading to dysregulation.

Recent in silico pathway analysis suggests that PDSS2 interacts with $\mathrm{HNF} 4 \alpha$, a nuclear transcription factor that acts as a tumor suppressor and regulates the expression of many genes involved in cell growth and proliferation $(20,32)$. CDX2 is a tumor suppressor of various malignancies and interacts with $\mathrm{HNF} 4 \alpha(28,33)$. Accordingly, the correlations of mRNA expression between PDSS2, HNF4 $\alpha$ and $C D X 2$ were evaluated, and we found that the expression of PDSS2 correlated positively with that of HNF4 $\alpha$. These findings support the function of PDSS2 as a suppressor of HCC, and further pathway analysis will be required to support this conclusion.

PDSSs are heterotetrameric enzymes comprising subunits encoded by PDSS1 (10p12.1) and PDSS2 $(15,16)$. In the absence of prenyl diphosphate synthase activity, CoQ10 is not synthesized (15). Therefore, decreased expression of PDSS2 in the liver tissues may lead to reduced synthesis of CoQ10 by hepatocytes, resulting in the inhibition of tumor suppressors $(17,18)$.

Similar to patients with malignant melanoma and lung cancer, most patients with HCC harbored decreased levels of PDSS2 mRNA in HCC tissues, and their mean level of PDSS2 expression was significantly decreased in HCC tissues compared with non-cancerous liver tissues $(16,20)$. Notably, we show here a stepwise decrease of PDSS2 expression accom- 
Table III. Prognostic factors of 151 patients with hepatocellular carcinoma (HCC).

\begin{tabular}{|c|c|c|c|c|c|c|c|}
\hline \multirow[b]{2}{*}{ Variables } & \multirow[b]{2}{*}{$\mathrm{n}$} & \multicolumn{3}{|c|}{ Univariate analysis } & \multicolumn{3}{|c|}{ Multivariable analysis } \\
\hline & & Hazard ratio & $95 \% \mathrm{CI}$ & $\mathrm{P}$-value & Hazard ratio & $95 \% \mathrm{CI}$ & P-value \\
\hline Age ( $\geq 65$ years) & 84 & 1.92 & $1.07-3.57$ & $0.030^{\mathrm{a}}$ & 1.70 & $0.92-3.25$ & 0.090 \\
\hline Gender (male) & 126 & 1.27 & $0.60-3.13$ & 0.553 & & & \\
\hline Background liver (cirrhosis) & 54 & 1.58 & $0.88-2.81$ & 0.123 & & & \\
\hline Pugh-Child's classification (B) & 11 & 0.93 & $0.28-2.32$ & 0.889 & & & \\
\hline $\operatorname{AFP}(>20 \mathrm{ng} / \mathrm{ml})$ & 70 & 1.90 & $1.07-3.42$ & $0.029^{\mathrm{a}}$ & 1.09 & $0.57-2.10$ & 0.785 \\
\hline PIVKA II (>40 mAU/ml) & 93 & 2.10 & $1.14-4.07$ & $0.016^{\mathrm{a}}$ & 1.20 & $0.62-2.49$ & 0.595 \\
\hline Tumor multiplicity (multiple) & 34 & 2.09 & $1.11-3.76$ & $0.023^{\mathrm{a}}$ & 1.80 & $0.92-3.41$ & 0.085 \\
\hline Tumor size $(\geq 3.0 \mathrm{~cm})$ & 104 & 2.20 & $1.13-4.71$ & $0.020^{\mathrm{a}}$ & 1.40 & $0.63-3.43$ & 0.418 \\
\hline Tumor differentiation (well) & 35 & 0.55 & $0.25-1.10$ & 0.095 & & & \\
\hline Growth type (invasive growth) & 24 & 1.44 & $0.69-2.76$ & 0.318 & & & \\
\hline Serosal infiltration & 37 & 2.51 & $1.32-4.61$ & $0.006^{\mathrm{a}}$ & 1.14 & $0.56-2.25$ & 0.712 \\
\hline Formation of capsule & 104 & 1.05 & $0.57-2.02$ & 0.884 & & & \\
\hline Infiltration to capsule & 83 & 1.20 & $0.67-2.18$ & 0.537 & & & \\
\hline Septum formation & 98 & 0.87 & $0.49-1.60$ & 0.651 & & & \\
\hline Vascular invasion & 37 & 3.40 & $1.87-6.07$ & $<0.001^{\mathrm{a}}$ & 1.85 & $0.94-3.66$ & 0.076 \\
\hline Margin status (positive) & 28 & 2.64 & $1.42-4.73$ & $0.003^{\mathrm{a}}$ & 2.60 & $1.36-4.84$ & $0.005^{\mathrm{a}}$ \\
\hline Decreased $P D S S 2$ in $\mathrm{HCC}$ & 56 & 2.52 & $1.41-4.52$ & $0.002^{\mathrm{a}}$ & 2.45 & $1.27-4.80$ & $0.008^{\mathrm{a}}$ \\
\hline
\end{tabular}

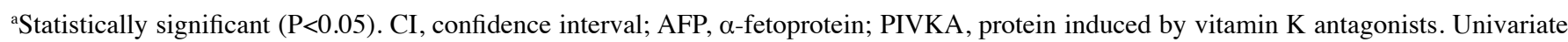
analysis was performed using the log-rank test. Multivariate analysis was performed using the Cox proportional hazards model.

panied with chronic inflammation and fibrosis of uninvolved liver. Moreover, our data link the level of PDSS2 expression to tumor differentiation. Taken together, these results suggest that PDSS2 plays a role in suppressing multistep hepatocarcinogenesis.

Because the IHC and qRT-PCR data were consistent, we used the latter to assess the prognostic significance of PDSS2 mRNA levels in a quantitative manner $(24,29)$. We found that decreased PDSS2 mRNA expression in HCCs was significantly associated with more aggressive tumor features, including elevated preoperative serum $\alpha$-fetoprotein, larger tumor size and serosal infiltration, and therefore, was identified as an independent prognostic factor. Moreover, patients with decreased PDSS 2 mRNA levels in their tumor tissues experienced significantly earlier recurrence after curative hepatectomy. Furthermore, the degree of the decrease in PDSS2 expression correlated with UICC stage, indicating that the level of PDSS2 expression reflects the severity of the malignant phenotype of HCC.

Our evidence that PDSS2 act as a tumor suppressor is as follows: i) decreased expression of PDSS2 was frequently detected and the mean level of PDSS2 expression was significantly lower in HCC tissues, and ii) decreased expression of PDSS2 was associated with shorter recurrence free survival and subsequent poor prognosis. PDSS2 expression levels in biopsy or resected tissues may be useful for the prediction of recurrence and poor prognosis, which will facilitate efforts to devise an efficacious therapeutic strategy.
Our data support the conclusion that PDSS2 acts as a tumor suppressor and that its expression is regulated by promoter hypermethylation in HCC. Moreover, decreased expression of PDSS2 mRNA may represent a novel biomarker for predicting the progression and recurrence of HCC.

\section{References}

1. Minguez B and Lachenmayer A: Diagnostic and prognostic molecular markers in hepatocellular carcinoma. Dis Markers 31: 181-190, 2011.

2. Kanda M, Nomoto S, Oya H, et al: Downregulation of DENND2D by promoter hypermethylation is associated with early recurrence of hepatocellular carcinoma. Int J Oncol 44: 44-52, 2014.

3. Jemal A, Bray F, Center MM, Ferlay J, Ward E and Forman D: Global cancer statistics. CA Cancer J Clin 61: 69-90, 2011.

4. El-Serag HB and Rudolph KL: Hepatocellular carcinoma: epidemiology and molecular carcinogenesis. Gastroenterology 132: 2557-2576, 2007.

5. Shiraha H, Yamamoto K and Namba M: Human hepatocyte carcinogenesis (Review). Int J Oncol 42: 1133-1138, 2013.

6. El-Serag HB: Hepatocellular carcinoma: recent trends in the United States. Gastroenterology 127: S27-S34, 2004.

7. Kanda M, Nomoto S, Nishikawa Y, et al: Correlations of the expression of vascular endothelial growth factor B and its isoforms in hepatocellular carcinoma with clinico-pathological parameters. J Surg Oncol 98: 190-196, 2008.

8. Llovet JM, Burroughs A and Bruix J: Hepatocellular carcinoma. Lancet 362: 1907-1917, 2003

9. Kanda M, Nomoto S, Okamura Y, et al: Promoter hypermethylation of fibulin 1 gene is associated with tumor progression in hepatocellular carcinoma. Mol Carcinog 50: 571-579, 2011. 
10. El-Serag HB and Mason AC: Rising incidence of hepatocellular carcinoma in the United States. N Engl J Med 340: 745-750, 1999.

11. Villanueva A, Newell P, Chiang DY, Friedman SL and Llovet JM: Genomics and signaling pathways in hepatocellular carcinoma. Semin Liver Dis 27: 55-76, 2007.

12. Miki D, Ochi $\mathrm{H}$, Hayes $\mathrm{CN}$, Aikata $\mathrm{H}$ and Chayama $\mathrm{K}$ : Hepatocellular carcinoma: towards personalized medicine. Cancer Sci 103: 846-850, 2012.

13. Kanda M, Nomoto S, Okamura Y, et al: Detection of metallothionein $\mathrm{GG}$ as a methylated tumor suppressor gene in human hepatocellular carcinoma using a novel method of double combination array analysis. Int J Oncol 35: 477-483, 2009.

14. Herath NI, Leggett BA and MacDonald GA: Review of genetic and epigenetic alterations in hepatocarcinogenesis. $\mathrm{J}$ Gastroenterol Hepatol 21: 15-21, 2006.

15. Saiki R, Nagata A, Kainou T, Matsuda $H$ and Kawamukai M: Characterization of solanesyl and decaprenyl diphosphate synthases in mice and humans. FEBS J 272: 5606-5622, 2005.

16. Fung JM, Smith R, Brown MA, et al: Identification and characterization of a novel melanoma tumor suppressor gene on human chromosome 6q21. Clin Cancer Res 15: 797-803, 2009.

17. Turunen M, Olsson J and Dallner G: Metabolism and function of coenzyme Q. Biochim Biophys Acta 1660: 171-199, 2004

18. Quinzii CM, DiMauro S and Hirano M: Human coenzyme Q10 deficiency. Neurochem Res 32: 723-727, 2007.

19. DiMauro S, Quinzii CM and Hirano M: Mutations in coenzyme Q10 biosynthetic genes. J Clin Invest 117: 587-589, 2007.

20. Chen P, Yu J, Knecht J and Chen Q: Decrease of PDSS2 expression, a novel tumor suppressor, in non-small cell lung cancer. Cancer Epidemiol 37: 166-171, 2013.

21. Takami H, Kanda M, Oya H, et al: Evaluation of MAGE-D4 expression in hepatocellular carcinoma in Japanese patients. $\mathbf{J}$ Surg Oncol 108: 557-562, 2013.

22. Sobin LH, Gospodarowicz MK and Wittekind CH: International Union Against Cancer: TNM Classification of Malignant Tumors. 7th edition. Wiley-Blackwell, New York, 2009.
23. Oya H, Kanda M, Takami H, et al: Overexpression of melanomaassociated antigen D4 is an independent prognostic factor in squamous cell carcinoma of the esophagus. Dis Esophagus: Oct 2, 2013 (Epub ahead of print). doi: 10.1111/dote.12156.

24. Kanda M, Shimizu D, Nomoto S, et al: Prognostic impact of expression and methylation status of DENN/MADD domaincontaining protein 2D in gastric cancer. Gastric Cancer: Apr 3, 2014 (Epub ahead of print).

25. Shimizu D, Kanda M, Nomoto S, et al: Identification of intragenic methylation in the TUSC1 gene as a novel prognostic marker of hepatocellular carcinoma. Oncol Rep 31: 1305-1313, 2014.

26. Takai D and Jones PA: The CpG island searcher: a new WWW resource. In Silico Biol 3: 235-240, 2003.

27. Hibino S, Kanda M, Oya H, et al: Reduced expression of DENND2D through promoter hypermethylation is an adverse prognostic factor in squamous cell carcinoma of the esophagus. Oncol Rep 31: 693-700, 2014.

28. Saandi T, Baraille F, Derbal-Wolfrom L, et al: Regulation of the tumor suppressor homeogene $\mathrm{Cdx} 2$ by HNF4alpha in intestinal cancer. Oncogene 32: 3782-3788, 2013.

29. Kanda M, Shimizu D, Nomoto S, et al: Clinical significance of expression and epigenetic profiling of TUSC1 in gastric cancer. J Surg Oncol 110: 136-144, 2014.

30. Nagai H, Pineau P, Tiollais P, Buendia MA and Dejean A: Comprehensive allelotyping of human hepatocellular carcinoma. Oncogene 14: 2927-2933, 1997.

31. Li SP, Wang HY, Li JQ, et al: Genome-wide analyses on loss of heterozygosity in hepatocellular carcinoma in Southern China. J Hepatol 34: 840-849, 2001.

32. Walesky C, Edwards G, Borude P, et al: Hepatocyte nuclear factor 4 alpha deletion promotes diethylnitrosamine-induced hepatocellular carcinoma in rodents. Hepatology 57: 2480-2490, 2013.

33. Ehehalt F, Rummele P, Kersting S, et al: Hepatocyte nuclear factor (HNF) 4alpha expression distinguishes ampullary cancer subtypes and prognosis after resection. Ann Surg 254: 302-310, 2011. 